Article

\title{
Study of the Effect of Physicochemical Degradation and Contamination of Motor Oils on Their Lubricity
}

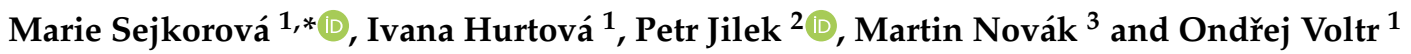 \\ 1 Department of Transport Means and Diagnostics, Faculty of Transport Engineering, University of Pardubice, \\ Studentská 95, 53210 Pardubice, Czech Republic; ivana.hurtova@upce.cz (I.H.); ondrej.voltr@upce.cz (O.V.) \\ 2 Educational and Research Centre in Transport, Faculty of Transport Engineering, University of Pardubice, \\ Studentská 95, 53210 Pardubice, Czech Republic; petr.jilek@upce.cz \\ 3 Department of Transport Management, Marketing and Logistics, Faculty of Transport Engineering, \\ University of Pardubice, Studentská 95, 53210 Pardubice, Czech Republic; novak@upce.cz \\ * Correspondence: marie.sejkorova@upce.cz
}

Citation: Sejkorová, M.; Hurtová, I.; Jilek, P.; Novák, M.; Voltr, O. Study of the Effect of Physicochemical Degradation and Contamination of Motor Oils on Their Lubricity. Coatings 2021, 11, 60. https:// doi.org/10.3390/ coatings11010060

Received: 19 October 2020 Accepted: 31 December 2020

Published: 7 January 2021

Publisher's Note: MDPI stays neutral with regard to jurisdictional clai$\mathrm{ms}$ in published maps and institutional affiliations.

Copyright: (C) 2021 by the authors. Licensee MDPI, Basel, Switzerland. This article is an open access article distributed under the terms and conditions of the Creative Commons Attribution (CC BY) license (https:// creativecommons.org/licenses/by/ $4.0 /)$.

\begin{abstract}
Internal combustion engine lubrication is essential for unwanted energy and material losses. As part of the experimental work, the lubricity of both new and worn motor oils of Society of Automotive Engineers (SAE) 15W-40 and SAE 10W-40 with different American Petroleum Institute (API) performance classifications, which were taken from various motor trains during maintenance or oil change, was assessed. A total of sixteen lubricant samples were evaluated. Lubricity, i.e., the load capacity of the lubricating film, was evaluated on the basis of the Reichert test. Viscosity, as one of the most important parameters of lubricants, was evaluated by the Stabinger Viscometer. Chemical degradation of motor oils (oxidation, nitration, sulfation), contamination of oils with fuel, soot, water, and loss of antioxidant zinc dialkyldithiophosphate (ZDDP) were monitored by Fourier-transform infrared (FTIR) spectroscopy. Of the fresh motor oils, OMV 10W-40 API SL/CF motor oil had the best lubricity. URANIA LD 15W-40 API CI-4 and M7ADS V 15W-40 API CI-4 CH-4/SL oils showed similar lubricity. M7ADS III 15W-40 API CF-4/SG motor oil showed the highest wear of wear surface, i.e., the lowest lubricity, of the tested new motor oils. Correlation analysis of the experimental data confirmed that the fuel content penetrated the motor oils significantly negatively correlates with the viscosity $(R=-0.87)$. The low water contamination in motor oil does not cause a significant negative effect on lubricity. A significant correlation between the oxidation, nitration, and sulfation products of chemical degradation of the tested oils was confirmed $(\mathrm{R} \geq 0.90)$. These degradation products improve lubricity due to their polarity, i.e., they have caused better lubricity of worn oils compared to new motor oils. Even the depletion of the antioxidant ZDDP did not affect the reduction in lubricity and anti-abrasion properties of chemically degraded motor oils. The experimental results of testing of worn motor oils taken from motor trains showed that current motor oils have excellent lubricity, which they maintain throughout their life.
\end{abstract}

Keywords: lubricity; oil analysis; motor oil; lubricant degradation; wear; Reichert test

\section{Introduction}

The reliability of an internal combustion engine largely depends on good lubrication. Therefore, it is necessary for the motor oil to pass through the clearances continuously and intensively in the friction surfaces of the engine and to ensure a sufficiently strong film with lubricating properties so that the friction and wear of the moving parts of the mechanism are as small as possible. It is necessary not only at normal operating temperatures but also at and just after starting a cold engine when limit lubrication occurs [1]. These limit states lead to several times more wear than the ones at normal oil operating temperatures [2]. In addition to lubrication, the motor oil must remove excess heat, protect surfaces from the effects of pressure, chemical attack, clean the inside of the engine by removing products of thermal oxidation reactions between oil, fuel, and other impurities, neutralize acidic 
corrosive products generated during fuel combustion, i.e., it must have sufficient alkaline reserve, seal the space between the piston rings and the cylinder wall so that the penetration of compressed gases and pollutants is as small as possible, have low evaporation, dampen noise and vibrations [3].

The components used in the manufacture of motor oil are the base oil(s) and the polymeric and solid viscosity modifier dissolved therein, and chemical additives, which impart performance properties to the motor oil [4-6].

Lubrication of the internal combustion engine is essential to reduce unwanted energy and material losses, i.e., to increase its fuel efficiency and service life [7-9]. From this point of view, two types of additives are essential that are mixed into the lubricating motor oil; these are friction modifiers and anti-wear additives [10]. Friction modifiers are functionalized polymers, soluble organic molybdenum additives, or dispersed nanoparticles, with the task of reducing the coefficient of friction between moving engine components and thus reducing undesired energy losses. Anti-wear additives reduce the wear of engine components, i.e., extend their life. Zinc dialkyldithiophosphate (ZDDP) has been commonly used as an anti-wear additive since the mid-20th century [11]. This additive relatively easily forms a tribofilm between the sliding surfaces, i.e., a protective barrier which prevents metal-to-metal contact and consequent wear of the moving parts. A detailed description of the mechanism of the ZDDP effect is given, for example, in these publications [12-14]. Thersleff et al. [15] stated that drained lubricants containing ZDDP can potentially be a source of unidentified risks.

During the usage of the engine, the oil is exposed to the strong oxidizing effect of oxygen and intense thermal stress. The thermal oxidation process significantly catalytically affects iron $(\mathrm{Fe})$, copper $(\mathrm{Cu})$, acidic substances, water, fuel, and mechanical impurities. Oxidation of the oil is accompanied by its darkening, increase in its acidity and viscosity, odor, and discharge of insoluble oxidation products. Oxidation products lead to the formation of deposits. Furthermore, sticky sludges and varnishes are formed, which impair the homogeneity of the oil and clog the filter inserts. Intensive thermal oxidation action occurs, especially in the piston group, where the weak oil layer is exposed to high oxidation and thermal stress in the presence of other substances that can catalytically affect the oxidation [16]. In addition to the actual chemical aging of the oil, it is also degraded by residues of imperfectly burned fuel, condensed water or coolant penetrating leaks, metal wears particles of engine components, small dust impurities sucked from the environment, and soot in diesel engines [16-18].

Viscosity is one of the most important properties affecting the flow properties of substances. The viscosity of the oil may change due to pressure and temperature [7]. These dependencies determine the properties of the used oil. Viscosity can increase or decrease during operation. The products of condensation and polymerization reactions, which take place under high thermal stress of the oil, and oxidation products contribute to the increase in viscosity. Jakóbiec et al. [19] stated that soot generated in the engine can cause hard sludge, high lubricant viscosity, or oil gelling. Insoluble sludges generally do not cause a significant increase in viscosity when the soot particles are individually dispersed due to dispersing additives. The viscosity can be increased by insoluble soot particles introduced into the lubricant in the piston ring area. Ziółkowska [20] stated that soot particles tend to agglomerate, which is the main cause of motor oil gelling at high temperatures. Soot-contaminated oil was studied in various researches on the use of antiwear additives [21-23]. According to Vyavhare et al. [24], increasing the concentration of soot in formulated oils increases the wear of the sliding surfaces significantly. According to Bagi et al. [21], the wear caused by soot occurs through an abrasive wear mechanism, where the soot antagonistically interacts with the protective tribofilms formed by the anti-wear additives and makes the wear of the engine components worse. Penchaliah et al. [25] reported in their study that soot and oxidation products in the lubricant cause abrasive and polishing wear, while sulfuric acid and moisture cause corrosion wear on machine 
components. Thickening of motor oils also occurs when the base oil has a high evaporation rate [26].

The reduction in viscosity is due to the dilution of oil with fuel [27], the depolymerization of the polymer additive used as a viscosity index modifier, or also due to cracking of the oil under thermal stress. The application of regenerative fuels and new exhaust after-treatment systems, frequent cold starts or a fault in the injector will cause the oil to be diluted with fuel, and this may lead to the lubricating film being too thin [28,29]. It may result in a breakage of the lubricating film and increased wear or even jamming of moving parts at higher stress. Soot is formed in a significant amount in lubricant cracking, contributing to increasing the viscosity of the motor oil.

In real conditions, motor oil is affected by many opposing influences. Understanding the degradation processes that occur in motor oil in operation is important with respect to meeting current and future requirements. Researchers are also studying motor oil degradation with a view to optimizing the replacement intervals [29-31] and setting up the maintenance systems [32-35].

The very current issue is the research of the effect of oil degradation on tribological properties because the development and testing of internal combustion engine components usually rely on fresh motor oils, regardless of the differences in lubricating properties caused by degradation.

Fernandes et al. [36] studied the lubricity of the new motor oil SAE 10W-40 (API) CI-4 and the same oil after $500 \mathrm{~h}$ of engine testing. The friction and wear of the piston ring and cylinder liner were evaluated on a short piston tester with the above oils. The fresh oil formed more ZDDP-derived tribofilms that mitigated liner wear but increased friction. Samples of a liner with accumulated 500 engine hours presented intermediate values of friction, wear, and ZDDP tribofilm elements. Ma et al. [37] stated that due to the depletion of antioxidants, the original lubricating and anti-wear additives are also depleted because both properties of the motor oil are usually provided by the same additive-ZDDP. This is reflected in a gradual increase in the coefficient of friction and thus in the engine noise.

Dörr et al. [12] studied ZDDP degradation and its effect on tribofilm formation and possible impact on friction and wear. Commercial motor oil SAE 0W-20 was used to produce a series of modified lubricants that were subjected to high-resolution mass spectrometry to identify ZDDP degradation products and their amounts over time. Selected oils were subjected to tribometric experiments. ZDDP concentrations, as well as the type and amount of ZDDP degradation products in oils, directly affected tribofilm formation and subsequent friction and wear. With the exception of sulfur, the amounts of phosphorus, zinc, and calcium decreased with the increasing degree of oil degradation, indicating that tribofilm formation became increasingly difficult.

For the understanding of motor oil SAE 5W-30 degradation in a combustion engine, in particular, ZDDP deterioration and its impact on wear expressed as iron content, a field test with a passenger car was carried out, which covered a distance of 19,800 km and represented an entire oil change interval [38]. Wear remained largely low when an intact ZDDP was available for tribofilm formation. The lack of ZDDP, together with the formation of inorganic acids from ZDDP, led to the fourfold increase in wear rate.

In the current literature, we can find divergent views on the change in lubricity due to the increase in oxidative degradation. Berglund [39] or Wang [40] studied the effect of oxidative degradation on the load-bearing capacity of the lubricating film. In both works, samples of a certain degree of degraded lubricant were created, which were further investigated in terms of the load-bearing capacity of the lubricating film. The results describe the increase in friction in both cases, with the maximum increase occurring by up to $80 \%$ of the original value for pure oil. Sikora [41] and Černý et al. [42] came to the opposite results. Sikora [41] studied the lubricity of Shell Helix AV-L motor oil operated in the Volkswagen Touran passenger car. The author stated that at the end of the change interval (approximately after $21,000 \mathrm{~km}$ ), the lubricity was $81 \%$ higher compared to the lubricity of fresh oil. However, the author did not comment on possible causes for this condition. 
The research of Černý et al. [42] focused on monitoring the lubricity and anti-abrasion properties of motor oils during their operation. Both viscosity measurements, including determination of high-temperature high shear (HTHS) viscosity, and measurements of oil friction coefficient during operation and lubricity according to the Reichert test, were performed. The oil friction coefficient roughly followed the kinematic viscosity values. The authors stated that due to the shear instability of modern motor oils, the largest viscosity changes occur at the beginning of oil operation. All operating samples of motor oil had a significantly lower coefficient of friction and smaller wear surface than new and unused oil. In further operation, the coefficient of friction of the oil and the size of the wear surface were kept at the same level. At the end of their service life, the studied motor oils had paradoxically better lubricity characteristics than the new oils.

Different opinions on the change in viscosity due to the increase in oxidative degradation also appear in other works. In his work [43], Höhn analyzed five transmissions mineral oils intended for various applications, each of which has undergone degradation at two different temperatures. The results show an increase in viscosity with a decrease in the ingredients contained in all oils and both temperatures. The same results are also presented by KEW Engineering [44]. The opposite results were obtained in the study by Sikora et al. [45], who tested various species of motor oils in the temperature range from 10 to $90{ }^{\circ} \mathrm{C}$. These samples represented the oil level driven in a car after 261 to $1319 \mathrm{~h}$. The results showed the dependence of the decrease in viscosity to an increasing degree of lubricant degradation at all measured temperatures, speeds, and pressures. Maguire [46] also mentions in his work a serious impact of oxidative degradation on the properties of the lubricant. For lubricants degraded by standard oxidation procedures (rotary pressure vessel, turbine stabilization test, thermal test, and many others) have been reduced for some oil's kinematic viscosities up to $100 \%$, but these changes could not be fully quantified, and general conclusions cannot be drawn from them.

While studying the literature, the authors of the paper found that one of the unanswered questions in the scientific field of lubrication remains: Why, in some cases, do operating (degraded) motor oils have better lubricating properties at the end of the recommended change interval than the new motor oils? To answer this question, it is necessary to study and understand the degradation processes that occur in motor oil in operation because tribological properties may be closely related to the condition of the motor oil.

\section{Materials and Methods}

To answer the above-mentioned research question, it was necessary to collect samples of new and worn motor oils with different levels of degradation, i.e., different kilometers on the oil filling. The lubricity of the tested samples was evaluated on the basis of the Reichert test. FTIR spectrometry was used to study degradation processes (oxidation, nitration, sulfation, ZDDP loss) and contamination of motor oils (by water, fuel, and soot). One of the most important physical parameters of motor oils-kinematic viscosity was also monitored. Correlation analyses of the obtained parameters of motor oils were used to determine the degree of dependence between chemical degradation, depletion of antioxidant and anti-wear additive ZDDP, contamination of motor oils, and wear of friction surfaces, i.e., lubricity.

\subsection{Tested Samples of Motor Oils}

To evaluate the influence of physicochemical degradation and contamination of motor oils on their lubricity, twelve samples of worn lubricants were taken from Czech Railways motor trains. Four fresh motor oils no. 1-1, 2-1, 3-1, 4-1 were used as a reference. Motor oils (M7ADS III, M7ADS V, Urania LD) of viscosity class SAE 15W-40, which had different American Petroleum Institute (API) specifications, and motor oils (OMV) of viscosity class SAE 10W-40, API SL/CF were evaluated (see Table 1). The worn oils were collected as a part of train maintenance. To ensure different levels of degradation and contamination, motor oils were taken at one-third, two-thirds, and almost at the end of the replacement 
interval from the different types of motor trains listed under the number in Table 1. For M7ADS III and M7ADS V motor oils, a change interval of 30,000 km is recommended, for Urania LD and OMV oils, after 40,000 km.

Table 1. Specifications of tested motor oils.

\begin{tabular}{|c|c|c|c|c|c|}
\hline Oil Sample No. & Motor Oil & Specifications & $\begin{array}{c}\text { New/Worn Motor } \\
\text { Oil }\end{array}$ & $\begin{array}{l}\text { Oil Drain Mileage } \\
(\mathbf{k m})\end{array}$ & Motor Train No. \\
\hline $1-1$ & M7ADS III & $\begin{array}{l}\text { SAE 15W-40 } \\
\text { API CF-4/SG }\end{array}$ & new & 0 & - \\
\hline $1-2$ & M7ADS III & $\begin{array}{l}\text { SAE } 15 W-40 \\
\text { API CF-4/SG }\end{array}$ & worn & 20,800 & 742,144 \\
\hline $\begin{array}{c}1-3 \\
\text { model sample }\end{array}$ & $\begin{array}{c}\text { M7ADS III } \\
\text { sample }(1-2)+15.6 \\
\text { wt. } \% \text { diesel }\end{array}$ & $\begin{array}{l}\text { SAE 15W-40 } \\
\text { API CF-4/SG }\end{array}$ & worn & 20,800 & 742,144 \\
\hline $\begin{array}{c}1-4 \\
\text { model sample }\end{array}$ & $\begin{array}{c}\text { M7ADS III } \\
\text { sample }(1-2)+25.6 \\
\text { wt. } \% \text { diesel }\end{array}$ & $\begin{array}{l}\text { SAE 15W-40 } \\
\text { API CF-4/SG }\end{array}$ & worn & 20,800 & 742,144 \\
\hline $1-5$ & M7ADS III & $\begin{array}{l}\text { SAE 15W-40 } \\
\text { API CF-4/SG }\end{array}$ & worn & 24,750 & 742,144 \\
\hline $2-1$ & M7ADS V & $\begin{array}{c}\text { SAE } 15 W-40 \\
\text { API CI-4 CH-4/SL }\end{array}$ & new & 0 & - \\
\hline $2-2$ & M7ADS V & $\begin{array}{c}\text { SAE } 15 W-40 \\
\text { API CI-4 CH-4/SL }\end{array}$ & worn & 12,335 & 810,578 \\
\hline $2-3$ & M7ADS V & $\begin{array}{c}\text { SAE } 15 W-40 \\
\text { API CI-4 CH-4/SL }\end{array}$ & worn & 25,888 & 814,031 \\
\hline $2-4$ & M7ADS V & $\begin{array}{c}\text { SAE } 15 W-40 \\
\text { API CI-4 CH-4/SL }\end{array}$ & worn & 25,900 & 814,085 \\
\hline $3-1$ & URANIA LD & $\begin{array}{l}\text { SAE } 15 W-40 \\
\text { API CI-4 }\end{array}$ & new & 0 & - \\
\hline $3-2$ & URANIA LD & $\begin{array}{l}\text { SAE 15W-40 } \\
\text { API CI-4 }\end{array}$ & worn & 33,256 & 841,007 I \\
\hline $3-3$ & URANIA LD & $\begin{array}{l}\text { SAE 15W-40 } \\
\text { API CI-4 }\end{array}$ & worn & 33,260 & 841,007 II \\
\hline $3-4$ & URANIA LD & $\begin{array}{l}\text { SAE 15W-40 } \\
\text { API CI-4 }\end{array}$ & worn & 37,805 & $841,015 \mathrm{I}$ \\
\hline $3-5$ & URANIA LD & $\begin{array}{l}\text { SAE } 15 W-40 \\
\text { API CI-4 }\end{array}$ & worn & 37,805 & 841,015 II \\
\hline $4-1$ & OMV & $\begin{array}{l}\text { SAE 10W-40 } \\
\text { API SL/CF }\end{array}$ & new & 0 & - \\
\hline $4-2$ & OMV & $\begin{array}{l}\text { SAE 10W-40 } \\
\text { API SL/CF }\end{array}$ & worn & 39,800 & 841,097 \\
\hline
\end{tabular}

To evaluate the effect of motor oil contamination on lubricity, model samples no. 1-3, 1-4 were prepared by mixing worn oil no. $1-2$ with $15.6 \mathrm{~mL}$ of diesel and $25.6 \mathrm{~mL}$ of diesel.

The fresh motor oils differed in their viscosity classification according to the SAE (Society of Automotive Engineers, Warrendale, PA, USA); SAE 10W-40 motor oil is more fluid (has a lower viscosity) at lower temperatures than SAE 15W-40 viscosity class oil, and, therefore, ensures easy starts at low temperatures and is easier to transport through lubrication channels to lubricated areas. This protects the engine from wear during frequent cold starts. Motor oils also differed in the performance classification of the API (American Petroleum Institute, Washington, DC, USA). The performance class determines the load the oil is able to withstand without compromising its function. The API power classification divides motor oils according to motor type into petrol oils, marked with the letter S, and diesel oils, marked with the letter C. The performance level, i.e., lubricity, is expressed for the given motor type by another letter, from A upwards. In essence, in general, the further this letter is in the alphabet, the better the quality of the motor oil. If we evaluate motor oils 
according to this general rule, the quality should be approximately the same for M7ADS V (API CI-4 CH-4/SL) and Urania LD (API CI-4) motor oils. This would be followed by OMV (API SL/CF) motor oil, which according to the specification indicates that it is primarily intended for petrol engines, but can also be used in diesel engines. Last in terms of quality would be M7ADS III (API CF-4/SG) motor oil.

\subsection{Reichert Test}

The Reichert test was used to evaluate the lubricity of the analyzed motor oil samples listed in Table 1. The essence of testing on a Reichert M2 (Petrotest, Inc. GmbH, Dahlewitz, Germany) is a simulation of a real frictional contact of a fixed stationary roller (1) pressed against a rotating grinding ring (2) partly immersed in the tested lubricant (3). Figure 1 shows the workplace of the Reichert test. The PETROTEST methodology was used to evaluate the load capacity of the oil film. The load-bearing capacity of the lubricating film (BCLF) is defined by Formula (1). The equation shows that the load-bearing capacity of the lubricating film is inversely related to the size of the elliptical wear surface (WS) on the fixed stationary roller. For this reason, only WS values, according to Formula (2), are presented in the paper.

$$
\begin{aligned}
\mathrm{BCLF} & =\frac{2000 \cdot G \cdot 9.81}{\mathrm{WS}}, \\
\mathrm{WS} & =0.75 \cdot l \cdot d,
\end{aligned}
$$

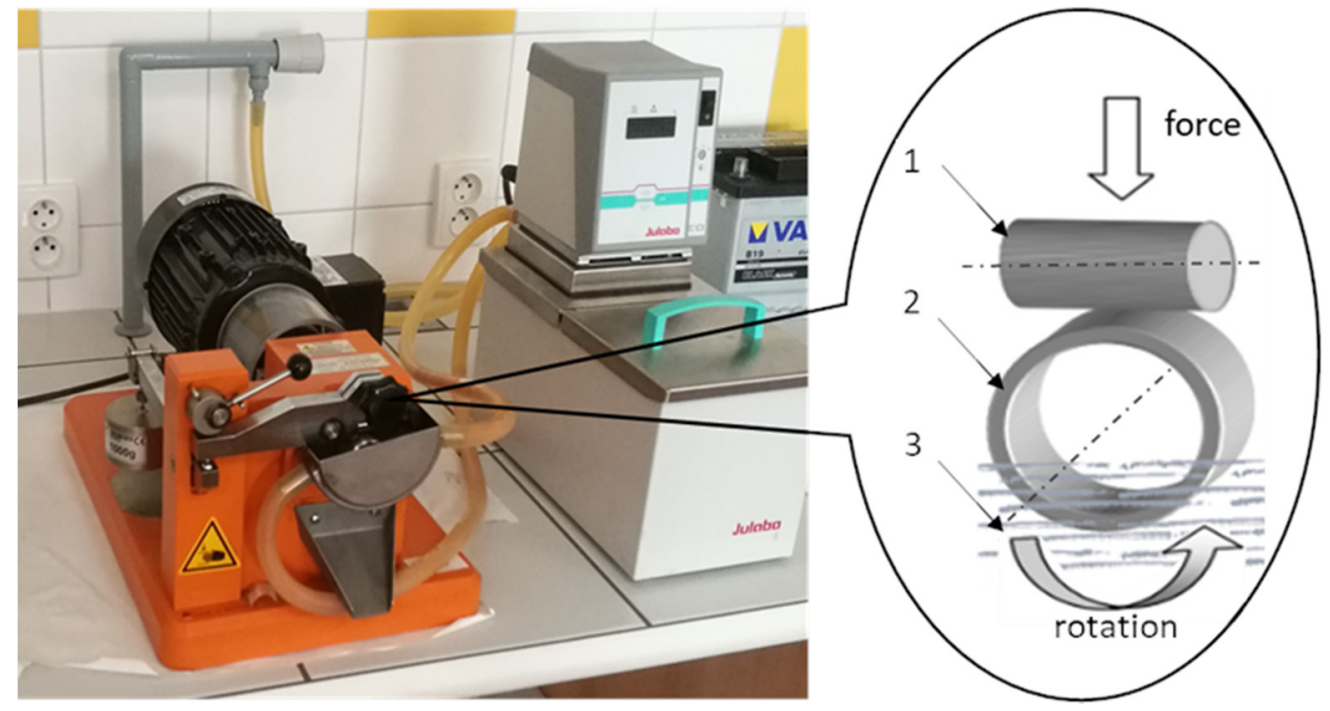

Figure 1. The workplace of the Reichert test.

BCLF is the load-bearing capacity of the lubricating film in $\left(\mathrm{N} \mathrm{cm}^{-2}\right), G$ corresponds to the selected load in $(\mathrm{kg})$, WS is the wear surface in $\left(\mathrm{mm}^{2}\right), l$ is the length of the elliptical surface in $\mathrm{mm}, d$ is the width of the elliptical surface in $\mathrm{mm}$.

The conditions of the Reichert test were load: $1.0 \mathrm{~kg}$; friction track: $100 \mathrm{~m}$; sliding speed: $800 \mathrm{rpm}$; sample volume: $25 \mathrm{~mL}$; temperature: $20{ }^{\circ} \mathrm{C}$; material of ringlet-grinding ring: steel, Petrotest 150023; material of rollers: steel-Petrotest 150021.

The measurement of lubricity expressed by the size of the wear surface on the stationary test roller was repeated three times, and the result is an average value.

Photo documentation of the wear surfaces on the test rollers was made with a digital microscope with a USB connection.

\subsection{Viscosity Measurement}

The dynamic viscosity (DV) measurement of motor oil samples was performed with an automatic SVM 3000 Anton Paar rotary Stabinger viscometer (Anton Paar, Graz, Austria). 
The measurement procedure was performed in accordance with ASTM D7042 [47]. When converting the values of dynamic viscosity to kinematic viscosity (KV) at $100{ }^{\circ} \mathrm{C}$, it is necessary to know the appropriate density $\rho$. For this reason, the SVM 3000 had an integrated density cell based on the proven and precise principle of oscillating U-tube. Both cells were filled with the sample in one measuring cycle.

From the measured DV and density values, the device automatically calculated KV at $100{ }^{\circ} \mathrm{C}$. The measurement took place in the temperature range from 15 to $100{ }^{\circ} \mathrm{C}$ at $p \approx 0.1 \mathrm{MPa}$.

\subsection{FTIR Spectroscopy}

FTIR spectroscopy was used to evaluate the degradation of lubricants, to monitor the penetration of contaminants into the oil filling, and to determine the concentration of the antioxidant additive ZDDP. Infrared (IR) spectra of all motor oil samples were recorded on a Nicolet iS10 spectrometer (Thermo Scientific, Inc., Waltham, MA, USA) using the attenuated total reflection technique (ATR), ZnSe crystal. The instrument was equipped with OMNIC software (version 8), which allows setting the parameters of the spectrometer, controls its own measurements, and performs the required subsequent operations with the spectra. The spectra of motor oil samples were measured in the spectral range of 4000 to $650 \mathrm{~cm}^{-1}$. Measurement parameters: resolution $4 \mathrm{~cm}^{-1}$, number of spectrum accumulations 64 .

The captured spectra were subsequently processed by the "OIL ANALYZER" computer program, which is part of the OMNIC program. Based on the internal methodology of "OIL ANALYZER", these parameters were determined: oxidation products (A.u./0.1 mm), nitration products (A.u./0.1 mm), sulfation products (A.u./0.1 mm), antioxidant (\%), soot $(\% \mathrm{~T})$, water (wt.\%), and fuel (wt.\%).

Oxidation, nitration, and sulfation were determined by a methodology based on subtracting the IR spectrum of fresh oil from the spectrum of worn oils, all baselinecorrected. For oxidation, the intensity of the absorption band at $1720 \mathrm{~cm}^{-1}$, for nitration the intensity of the absorption band at $1630 \mathrm{~cm}^{-1}$, and for sulfation, the intensity of the absorption band at $1150 \mathrm{~cm}^{-1}$ was then measured.

Residual amounts of antioxidants ZDDP were also monitored. Per definition, the amount in the fresh oil was set to $100 \%$, and, subsequently, the content in worn oil samples was related to the respective fresh oil and expressed in percent. The absorption band of ZDDP can be found in the range of 1020 to $920 \mathrm{~cm}^{-1}$.

The spectral region around $2000 \mathrm{~cm}^{-1}$ was used to assess the level of soot particles in the motor oil. Although soot particles have no specific absorption frequencies in the infrared spectrum, a spectral region around $2000 \mathrm{~cm}^{-1}$ was used to evaluate the level of soot particles in motor oil, as no other spectral phenomena occur in this region. Soot in motor oil causes the baseline of the spectrum to shift due to light absorption and scattering. The spectrum of fresh motor oil has a value of $100 \% \mathrm{~T}$ in the region of $2000 \mathrm{~cm}^{-1}$. As the concentration of soot particles in the lubricant increases, the transmittance decreases.

Diesel (wt.\%) in motor oil was determined by internal methodology [48]; the spectral region $835-688 \mathrm{~cm}^{-1}$ was determined. Water was detected as a broad spectral band in the region of 3600-3150 $\mathrm{cm}^{-1}$ due to the hydroxyl (-OH) group. Water concentration (wt.\%) was determined from the intensity of the spectral band at $3400 \mathrm{~cm}^{-1}$, corrected for baseline.

\subsection{Data Processing}

The experimental data were subjected to correlation analysis. Pearson's correlation coefficient $(\mathrm{R})$ measures the degree of tightness of the linear relationship between the variables of the motor oils tested. When calculating the Pearson correlation coefficient, we generally start from measured values on $\mathrm{n}$ units for pairs of variables $\mathrm{x}$ and $\mathrm{y}$ (Formula (3)).

$$
\left(\begin{array}{l}
x_{1} \\
y_{1}
\end{array}\right),\left(\begin{array}{l}
x_{2} \\
y_{2}
\end{array}\right), \ldots,\left(\begin{array}{l}
x_{n} \\
y_{n}
\end{array}\right),
$$


Pearson's correlation coefficient (Formula (4)) is then calculated as "normalized covariance"-i.e., covariance divided by the product of the standard deviations of both variables. After editing, the formula looks like this:

$$
\mathrm{R}=\frac{\sum_{\mathrm{i}=1}^{\mathrm{n}}\left(\mathrm{x}_{\mathrm{i}}-\overline{\mathrm{x}}\right) \cdot\left(\mathrm{y}_{\mathrm{i}}-\overline{\mathrm{y}}\right)}{{\sqrt{\sum_{\mathrm{i}=1}^{\mathrm{n}}\left(\mathrm{x}_{\mathrm{i}}-\overline{\mathrm{x}}\right)^{2} \cdot \sum_{\mathrm{i}=1}^{\mathrm{n}}\left(\mathrm{y}_{\mathrm{i}}-\overline{\mathrm{y}}\right)^{2}}}^{2}}
$$

where $x_{i}$ is the value of an $i$-th variable $x, y_{i}$ is the value of an $i$-th variable $y, x$ is the average value of the variable $x, y$ is the average value of the variable $y, n$ is the number of samples tested.

We can then test the significance ( $p$-value) of the calculated R. If the $p$-value is less than the significance level $\alpha=0.05$, then the correlation is confirmed ( $R$ differs statistically significantly from zero). Microsoft Excel spreadsheet and STATISTICA 10.0 program were used for experiment data analysis.

\section{Results and Discussion}

Table 2 shows the complete results of analyses of four groups of motor oil samples (M7ADS III, M7ADS V, Urania LD, OMV) according to the Reichert test, $\mathrm{KV}$ at $100{ }^{\circ} \mathrm{C}$, and FTIR spectroscopy. Photo documentation of the wear surfaces (WS) on the test steel rollers from the Reichert test is given in Figure S1. The spectra of motor oils, on the basis of which the content of antioxidant and anti-wear additive ZDDP, soot, fuel, water, and oxidation, nitration, and sulfation products were determined is given in Figure S2.

Table 2. Results of testing motor oils.

\begin{tabular}{|c|c|c|c|c|c|c|c|c|c|}
\hline $\begin{array}{c}\text { Oil Sample } \\
\text { No. }\end{array}$ & $\begin{array}{c}\text { WS } \\
\left(\mathrm{mm}^{2}\right)\end{array}$ & $\begin{array}{l}\mathrm{KV}_{100}{ }^{\circ} \mathrm{C} \\
\left(\mathrm{mm}^{2} \cdot \mathrm{s}^{-1}\right)\end{array}$ & $\begin{array}{c}\text { ZDDP } \\
(\%)\end{array}$ & $\begin{array}{l}\text { Soot } \\
(\% T)\end{array}$ & $\begin{array}{c}\text { Fuel } \\
\text { (wt.\%) }\end{array}$ & $\begin{array}{l}\text { Water } \\
\text { (wt.\%) }\end{array}$ & $\begin{array}{l}\text { Oxidation } \\
\text { (A/0.1 mm) }\end{array}$ & $\begin{array}{l}\text { Nitration } \\
(\mathrm{A} / 0.1 \mathrm{~mm})\end{array}$ & $\begin{array}{l}\text { Sulfation } \\
\text { (A/0.1 mm) }\end{array}$ \\
\hline $1-1$ & 9.0 & 14.62 & 100.0 & 100 & 0.0 & 0.0 & 0.00 & 0.00 & 0.00 \\
\hline $1-2$ & 7.9 & 12.15 & 69.3 & 72 & 4.4 & 0.0 & 0.17 & 0.08 & 0.16 \\
\hline $1-3$ & 8.3 & 9.23 & 69.3 & 72 & 20.0 & 0.0 & 0.17 & 0.08 & 0.16 \\
\hline $1-4$ & 8.8 & 7.47 & 69.3 & 72 & 30.0 & 0.0 & 0.17 & 0.08 & 0.16 \\
\hline $1-5$ & 6.3 & 14.75 & 63.4 & 54 & 2.7 & 0.2 & 0.05 & 0.08 & 0.14 \\
\hline $2-1$ & 5.9 & 14.29 & 100.0 & 100 & 0.0 & 0.0 & 0.00 & 0.00 & 0.00 \\
\hline $2-2$ & 7.6 & 12.94 & 74.0 & 81 & 17.0 & 0.0 & 0.21 & 0.12 & 0.19 \\
\hline $2-3$ & 6.3 & 13.30 & 67.0 & 78 & 0.0 & 0.1 & 0.07 & 0.10 & 0.14 \\
\hline $2-4$ & 7.9 & 15.48 & 59.0 & 79 & 7.0 & 0.0 & 0.07 & 0.09 & 0.17 \\
\hline $3-1$ & 5.8 & 14.14 & 100.0 & 100 & 0.0 & 0.0 & 0.00 & 0.00 & 0.00 \\
\hline $3-2$ & 5.9 & 14.07 & 11.5 & 93 & 0.0 & 0.0 & 0.15 & 0.23 & 0.26 \\
\hline $3-3$ & 6.1 & 14.07 & 13.8 & 93 & 0.0 & 0.0 & 0.14 & 0.22 & 0.26 \\
\hline $3-4$ & 6.3 & 14.68 & 5.0 & 88 & 0.0 & 0.0 & 0.26 & 0.40 & 0.38 \\
\hline $3-5$ & 5.8 & 14.65 & 6.0 & 88 & 0.5 & 0.0 & 0.26 & 0.40 & 0.38 \\
\hline 4-1 & 3.5 & 14.37 & 100.0 & 100 & 0.0 & 0.0 & 0.00 & 0.00 & 0.00 \\
\hline $4-2$ & 2.1 & 15.58 & 23.2 & 75 & 0.0 & 0.2 & 0.42 & 0.62 & 0.57 \\
\hline
\end{tabular}

\subsection{Evaluation of Fresh Motor Oils Lubricity}

As follows from Formulas (1) and (2), the wear of machine parts is related to the load capacity of the lubricating film. Therefore, lubricity can be included among the most important parameters of lubricants, affecting the life of the tribological system [49]. The results of the Reichert test and the determination of $\mathrm{KV}$ at $100{ }^{\circ} \mathrm{C}$ testing of new motor oils are shown in Figure 2. 


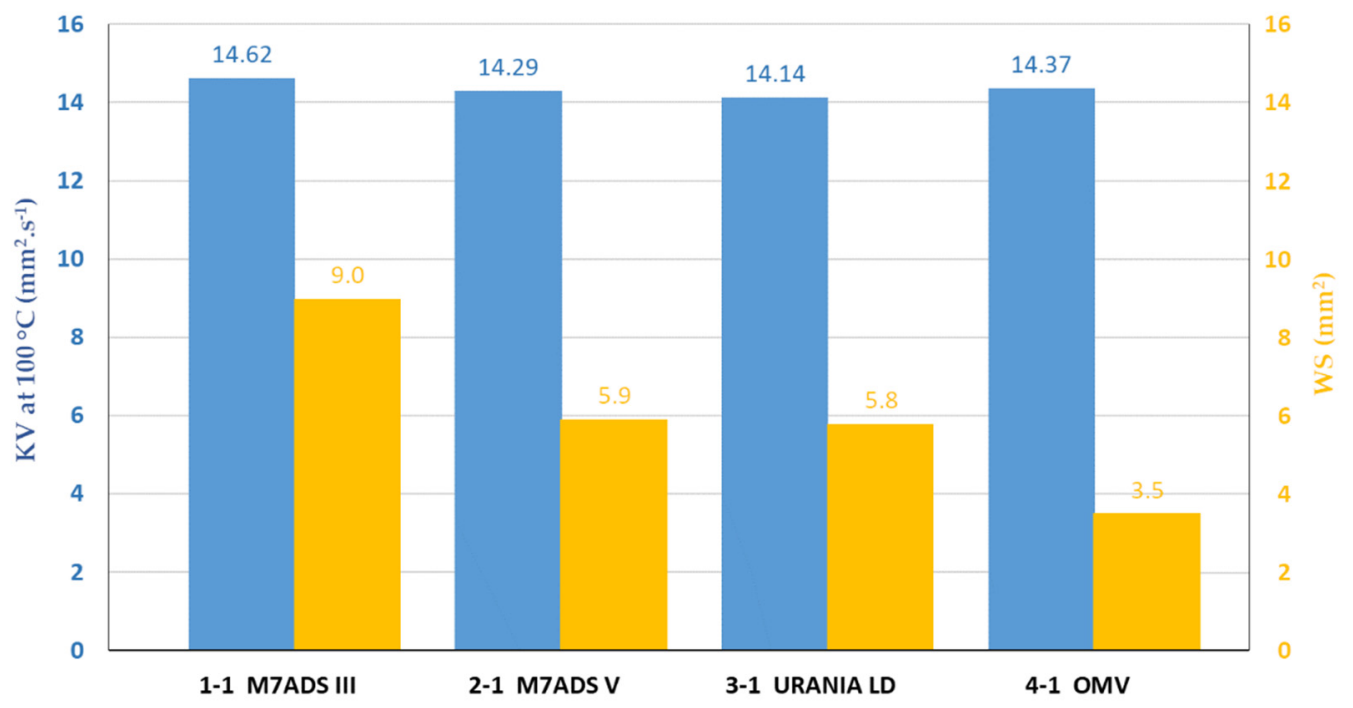

Figure 2. Results of lubricity evaluation of fresh motor oils.

The best lubricity was shown by OMV 10W-40 API SL/CF motor oil, which is recommended as a top lubricant for vehicles with extremely long change intervals. Mixtures of base oils in various combinations, such as polyalphaolefins (PAO) and hydrocracking oil, PAO and solvent raffinate, are most often used for the production of semi-synthetic oils [50]. From the group of motor oils of the SAE 15W-40 specification, the greatest wear of the wear surface of the cylinder was demonstrated by the motor oil M7ADS III. This type of oil is suitable for supercharged and non-supercharged diesel engines. Almost the same level of wear was recorded for M7ADS V and Urania LD mineral oils. M7ADS V motor oil is recommended for international transport vehicles that are exposed to extremely difficult operating conditions. Urania LD motor oil is unique in that it has a higher resistance to mechanical cutting. The basis for the production of M7ASD III and M7ADS V oils are hydrocracking oils. The viscosity of the lubricant has a fundamental effect on the lubrication process. If the lubricant has a low viscosity, the lubricant is forced out of the lubrication space, thereby reducing the lubricating film, which causes poor lubrication. This can damage the lubricated surfaces. High-viscosity lubricant has a harder time entering the lubrication space, resulting in insufficient lubrication. For this reason, it is necessary to monitor viscosity when studying the effect of degradation and contamination of motor oil on lubricity. The viscosity of the degraded oil should change by a maximum of $\pm 20 \%$ with respect to the viscosity of the new oil [51].

\subsection{Influence of Degradation and Contamination of Motor Oils on Lubricity}

In the case of testing samples of motor oils M7ADS III 15W-40 (no. 1-x), it can be seen that the highest wear of the test roller was when lubricating with new oil no. 1-1 (see Figure 3 and Table 2). On the contrary, the sample of worn motor oil no. 1-5 showed the best lubricity. It is the sample where the highest soot concentration $(54 \% \mathrm{~T})$ was found by FTIR spectroscopy; the literature [38] states the value of 30\% $\mathrm{T}$ as a limit value for the change of soot-contaminated oil. Soot belongs to the mechanical impurities, which are created in the combustion chamber during the combustion of diesel. It is, therefore, a problem with compression ignition engines; soot formation in spark-ignition engines is negligible. Most of the soot leaves the combustion chamber with the exhaust gases, but the remaining part, together with the exhaust gases, penetrates the crankcase, and the soot ends up in the motor oil. Problems with soot occur at higher concentrations, when, due to agglomeration, their size increases from several hundredths to one-tenth of the micrometer. According to Vyavhare et al. [24], the oxidation reactivity of soot in the crankcase is strongly dependent on changes in the physical and chemical composition of the carbon structure of the soot. There was a sufficient concentration of antioxidant and 
anti-wear additive ZDDP (63.4\%) in the oil sample no. $1-5$; fuel (2.7\%) and water $(0.2 \%)$ were also present in this sample. In the case of water, it is the permissible concentration limit. Water in motor oil can cause, for example, the precipitation of some additives in the form of deposits or sludge or the hydrolysis and degradation of other additives, which is typical of detergents. In studying the experimental behavior of water-contaminated lubricating films, Koutný [52] did not find that water droplets entered the contact area or affected the thickness of the lubricating film. The viscosity of this sample increased by only less than one percent compared to the new oil. This is confirmed by the fact that viscosity was affected by opposing effects; the fuel in the oil reduced the viscosity, while the soot increased it. Sample no. 1-2 contained about $4 \%$ of diesel oil, which is the limit value for an oil change. If the amount of fuel in the oil exceeds this limit, in most cases, it means a fault in the engine, usually in the injectors. The concentration of about $4 \%$ of fuel in the oil had the effect of reducing the viscosity by $17 \%$ compared to the viscosity of the new oil. In practice, in the case of large-volume compression ignition (CI) engines, the operation of the motor oil is usually permitted within the range of viscosity change of a maximum $\pm 20 \%$ compared to the viscosity of the new oil [35,51]. Another study [53] report an increase $(>35 \%)$ in $\mathrm{KV}$ at $100{ }^{\circ} \mathrm{C}$ as a warning limit. The limit value in passenger cars is a change in viscosity of a maximum $\pm 15 \%$ compared to the viscosity of the new oil. By comparing the test results of sample no. (1-2) and sample samples no. (1-3) and (1-4), which were prepared by mixing sample no. (1-2) and defined volume of diesel fuel (see Table 1), it can be concluded that reducing the viscosity by up to $50 \%$ of the original value did not have a significant effect on reducing the load-bearing capacity of the lubricating film, i.e., on increasing the wear of the test cylinders.
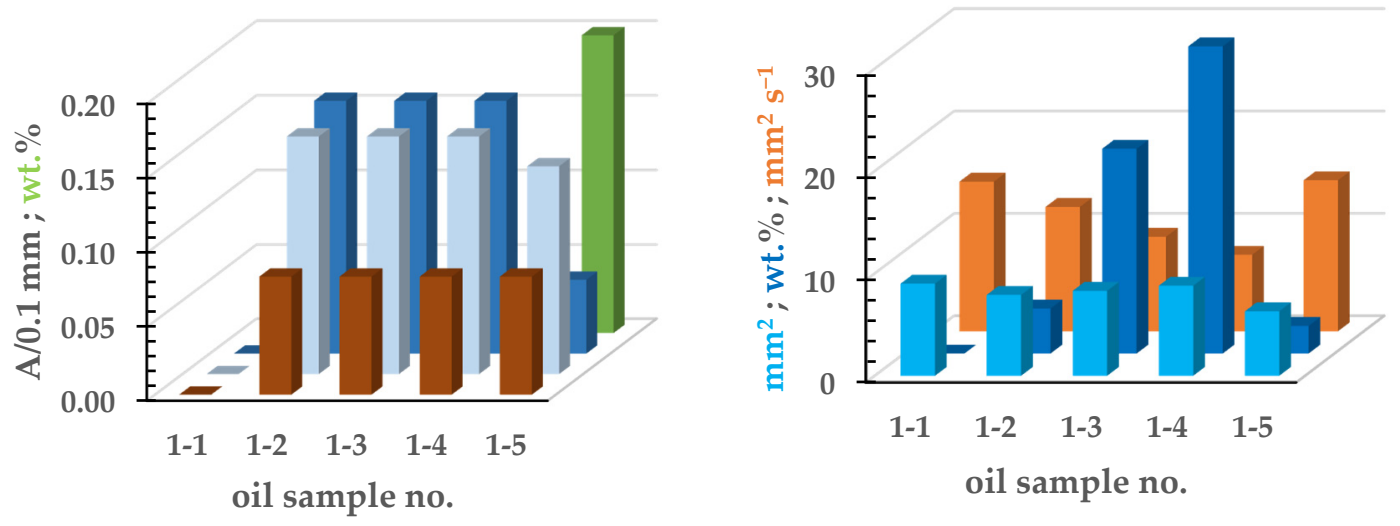

Nitration Sulfation $\square$ Oxidation $\square$ Water $\square$ WS Fuel $\quad \mathrm{KV} 100^{\circ} \mathrm{C}$

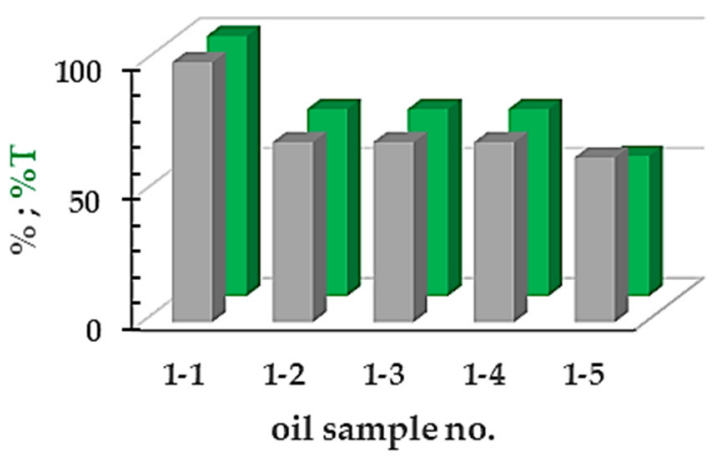

$\square$ Antioxidant $\quad \square$ Soot

Figure 3. Test results of motor oils M7ADS III - a comparison of monitored parameter values for motor oil samples 1-1 to 1-5 (where WS is wear surface and $\mathrm{KV}$ is kinematic viscosity at $100{ }^{\circ} \mathrm{C}$ ). 
In the case of testing used motor oils M7ADS V 15W-40 sample no. 2-2, 2-3, 2-4 (see Figure 4 and Table 2) with the distance of 12,335 km, 25,888 km, and 25,900 km, the concentration of the additive ZDDP was recorded at the level of $74 \%, 67 \%$, and $59 \%$, i.e., the limit value of $30 \%$ was not exceeded. Based on the fuel identification in the motor oil, two samples were diagnosed with a fault in the injectors. These were samples no. 2-2 and 2-4, in which the fuel concentration reached $17 \%$ and $7 \%$ and $\mathrm{KV}$ changed by about $-9 \%,+8 \%$ relative to the viscosity of the new oil. Oxidative degradation accompanied by sulfation and nitration could be observed in the sample of motor oil no. 2-2, which was in $1 / 3$ of its exchange interval. Oxidation of oil (hydrocarbons) produces various oxidation products, such as aldehydes, ketones, acids, esters, and others. Thanks to nitration from the flue gas, organic nitrates are also formed in the oil, which are also accompanied by sulfation products. The authors believe that, in addition to sulfur oxides (SOx) from exhaust gases, a gradual decrease in ZDDP contributes to the formation of these substances. When testing this group of motor oil samples, the maximum wear of $+34 \%$ with respect to the fresh oil was confirmed in borehole no. 2-4.
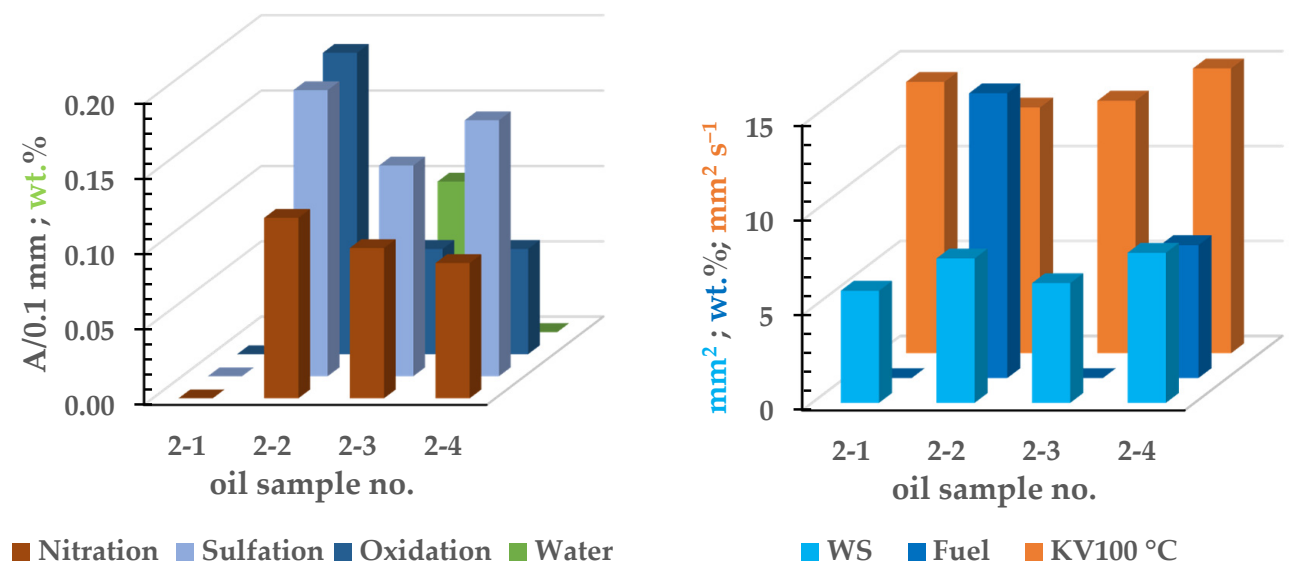

nitration $\square$ Sulfation $\square$ Oxidation $\square$ Water

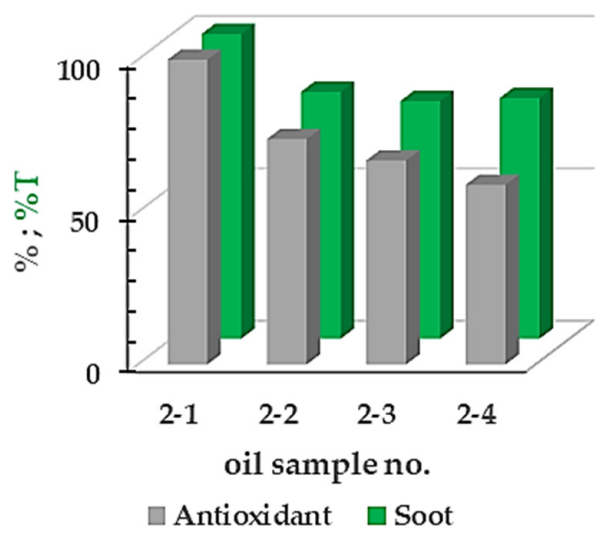

Figure 4. Test results of motor oils M7ADS V-a comparison of monitored parameter values for motor oil samples 2-1 to 2-4.The evaluation of the test results of used motor oils URANIA LD 15W-40 (see Figure 5) with the distance in the range of 33,000-37,810 km (samples 3-2 to 3-5) shows that they contain low soot content (98-88\% T). However, even a small amount of soot in the oil caused the oil to blacken. In all samples of this type of motor oil, the antioxidant and anti-abrasion additive ZDDP was reduced below the limit of 30\%, which is stated by Král et al. [54] as the limit value. Sejkorová [51] stated the ZDDP limit value of $20 \%$. The concentration of this additive ranged from 5 to $14.8 \%$. Depletion of ZDDP did not affect the wear of the wear surface of the steel rollers based on the Reichert test, probably due to the fact that the highest concentrations of oxidation, nitration, and sulfation products were found in these samples. However, the values did not reach the limit value of 1 A.u. $/ 0.1 \mathrm{~mm}$. The products of thermal oxidation degradation, nitration, and sulfation have a polar character and positively affect the load capacity of the lubricating film and the lubricity of oil in general, which reflects in the low level of wear of the test rollers. These degradation products did not occur in concentration that would have an impact on the change in viscosity of the evaluated oils; the change in viscosity ranged from -0.5 to $3.8 \%$ compared to the viscosity of the new oil. 

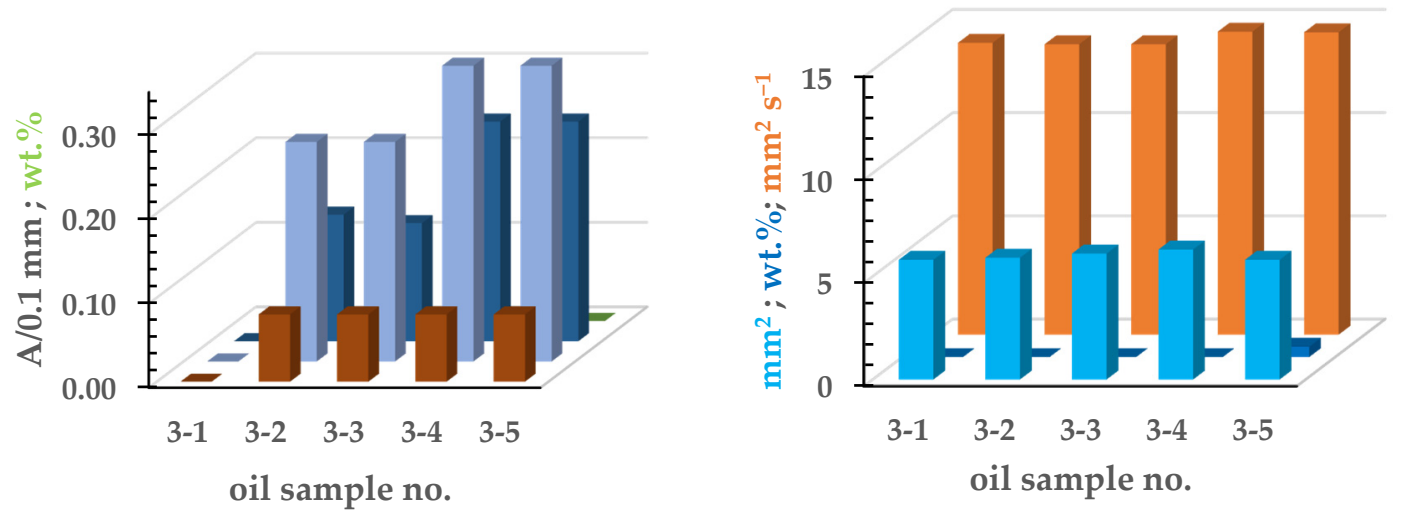

$\square$ Nitration $\square$ Sulfation $\square$ Oxidation $\square$ Water

WS Fuel $\quad \mathrm{KV} 100^{\circ} \mathrm{C}$

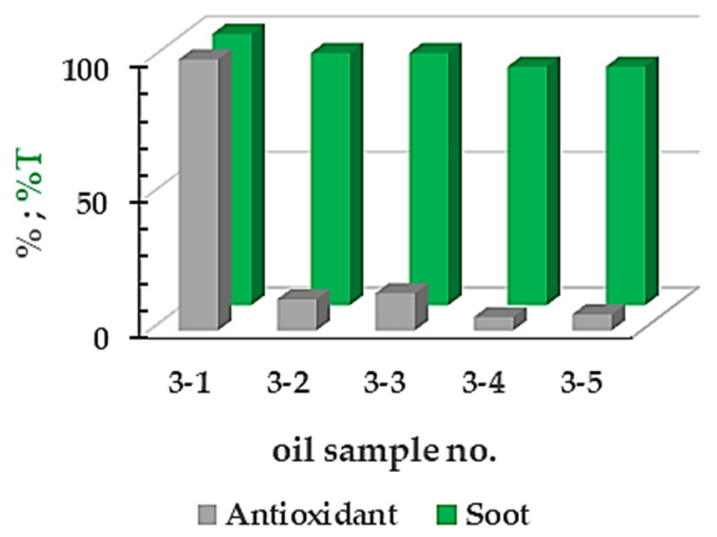

Figure 5. Test results of motor oils Urania LD—a comparison of monitored parameter values for motor oil samples 3-1 to $3-5$.

Of all the tested motor oils, the samples of oils OMV 10W-40 (no. 4-1, 4-2) showed the lowest wear, i.e., the best lubricity. Deducing from Table 2 and Figure 6, the ZDDP concentration decreased to $23.1 \%$ in the oil sample no. (4-2), but relatively high concentrations of oxidation, nitration, and sulfation polar products increased the adhesion of the motor oil, which reflects a $40 \%$ increase in lubricity compared to the new oil. Degradation products of used oil increased KV by only $8 \%$. Oxidative degradation and soot in the oil did not significantly affect the viscosity of motor oils.

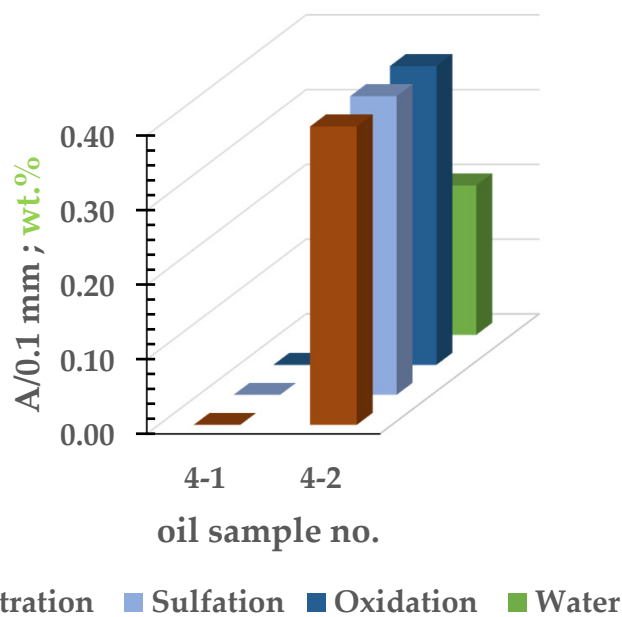

Figure 6. Cont. 


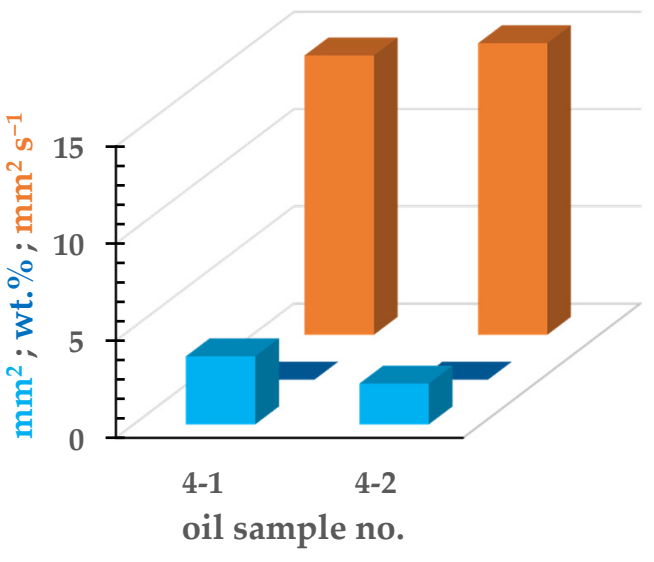

WS Fuel $\square \mathrm{KV} 100^{\circ} \mathrm{C}$

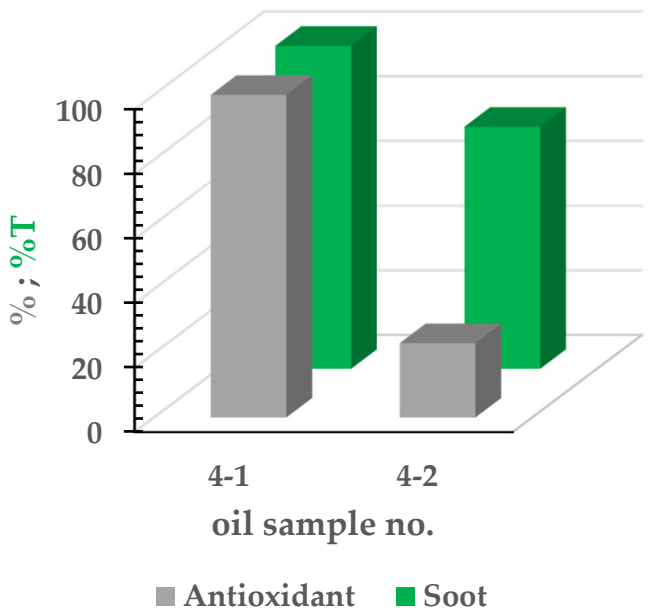

Figure 6. Test results of motor oils OMV—a comparison of monitored parameter values for motor oil samples $4-1$ to $4-2$.

In summary, we can say that contrary to expectations, the evaluated motor oils have retained excellent lubricating properties throughout their service life. These results are consistent with the results of Cerný et al. [42] and Sikora [41], who, however, did not provide experimentally substantiated justification for this condition. The authors, therefore, focused on the study of the most common form of lubricant degradation-the oxidationthat is the characteristic reaction of materials with oxygen, in which oxygen reacts with other molecules, resulting in the loss of an electron forming a free radical. Different functional groups, such as alcohols, aldehydes, ketones, carboxylic acid, and esters, are formed as a result of the above elementary reactions [55]. Oxidation of oil also contributes to the polarization of oils owing to the formation and/or depletion of the above functional groups. Oxidation occurs under mild conditions by the gradual depletion of antioxidants. In the case of motor oils, it is ZDDP, where this additive is also used as an anti-abrasion additive. Antioxidants are substances used to stabilize lubricants and prevent oxidation by reducing the activity of oxygen radicals. Once oxidation begins, it causes a severe and permanent chemical change in the base oil that results in the mentioned degradation. Simultaneously with the oxidation products, nitrates are formed, which have a very similar negative effect on the properties of the oil as the products of oil oxidation. Nitration occurs in the crankcase due to the presence of hot flue gases, which penetrate here from the engine cylinders. These bring the high temperature and exhaust gases (and with them $\mathrm{NO}_{x}$ ) to the crankcase. Due to the mixing of oil with air and hot flue gases, ideal conditions are created in the crankcase for oxidation as well as nitration. On the same principle, the authors $[30,54]$ 
presented the formation of sulfates, i.e., the formation of $\mathrm{SO}_{x}$ reactions from flue gases with oil. However, given the maximum concentration of $10 \mathrm{ppm}$ sulfur in the fuel, this seems unlikely [56]. The literature [50] showed that sulfation products accompany oxidation and nitration products. The authors noted that in most cases, with the mileage of the oil, the content of sulfation products increases, and the concentration of ZDDP decreases proportionally. Therefore, they concluded that the sulfation products are mainly the result of the reaction of sulfuric acid as a decomposition product of ZDDP with the base motor oil. All of these oxidative degradation products, in contrast to hydrocarbon molecules, have a positive polarity and, therefore, ensure better adhesion of the oil to lubricated tribological systems, which means they provide better lubricity. The products of condensation and polymerization reactions are formed under high thermal stress. These thermal degradation products, together with oxidation products, contribute to the increase in viscosity. However, the tested oils did not produce such amounts of oxidation products during the oxidative degradation that they would have a significant effect on the change in viscosity. Soot also contributes to increasing the viscosity of motor oils in a diesel engine. Soot generated in the engine can cause hard sludge, high lubricant viscosity, or oil gelling [20]. Contamination of the oil fill with soot did not cause a significant increase in viscosity due to the dispersants that dispersed them individually [57]. They have contradictory effects on viscosity. The decrease in viscosity was due to the dilution of the oil with fuel. The tested oils were shear resistant [3], i.e., there was no significant reduction in viscosity for oils not contaminated with diesel. The performed experiments confirmed that the water contaminating the motor oil does not come into contact in the between the friction surfaces and that the thickness of the lubricating film is sufficient to ensure lubrication, i.e., to prevent friction and wear.

\subsection{Correlation Analysis}

The correlation between the $\mathrm{x}, \mathrm{y}$ part of monitored parameters of motor oils was expressed by a correlation matrix (see Table 3 ). We assumed that the variables came from a normal distribution, so we calculated the correlation between the variables by the classical Pearson correlation coefficient $(R)$. The coefficient $R$ can take values from -1 to 1 . If $R>0$, $\mathrm{y}$ increases with increasing $\mathrm{x}$, if $\mathrm{R}<0$, as $\mathrm{x}$ increases, $\mathrm{y}$ decreases. The dependence with correlation coefficient in absolute value $|R|$ in the range of $<0.95-1\rangle$ is considered to be very strong, in the range of $<0.80-0.95>$ to be quite strong, and in the range of $<0.50-0.80>$ to be moderate dependence. If the value is $|\mathrm{R}|<0.5$, this dependence is considered insignificant [58]. We can then test the significance ( $p$-value) of the calculated R. If the $p$ value is less than the significance level $\alpha=0.05$, then the correlation is confirmed (R differs statistically significantly from zero). It should be noted that the existence of a significant correlation between variables does not necessarily imply a causal relationship between variables. Due to the fact that moisture appeared in only three samples, it was not included in the calculation. The authors also did not include a lubricity-related (WS) parameter in the calculation. The reason was the different value of this parameter for new samples.

Table 3. Correlation matrix

\begin{tabular}{cccccccc}
\hline Parameter & KV & ZDDP & Soot & Fuel & Oxidation & Nitration & Sulfation \\
\hline KV & 1 & - & - & - & - & - & - \\
ZDDP & -0.20 & 1 & - & - & - & - & - \\
soot & 0.34 & 0.15 & 1 & & - & - & - \\
fuel & $-\mathbf{0 . 8 7}$ & 0.18 & -0.45 & 1 & 1 & - & - \\
oxidation & -0.06 & $-\mathbf{0 . 7 2}$ & -0.35 & 0.16 & - & - \\
nitration & 0.30 & $\mathbf{- 0 . 8 3}$ & -0.14 & -0.22 & $\mathbf{0 . 9 0}$ & $\mathbf{0 . 9 4}$ & $\mathbf{0 . 9 7}$ \\
sulfation & 0.17 & $\mathbf{- 0 . 8 7}$ & -0.31 & -0.07 & $\mathbf{0 . 9 4}$ & 1 \\
\hline
\end{tabular}

Legend: The values in bold are statistically significant at $\alpha<0.05$.

Correlation analysis showed that the parameters of chemical degradation of tested oils (oxidation, nitration, and sulfation) correlated significantly with each other at the level of significance $\alpha<0.05$, and these parameters also correlated with the loss of antioxidant 
ZDDP, which is also used as the anti-wear additive. The very strong significant positive correlation $\mathrm{R}=0.90$ ( $p<<0.001$ ) between oxidation and nitration of the oil can be explained by the contact of the motor oil with the exhaust gases, which affects the entire oxidation process. Large oxidation changes in the oil occur where the temperature is very high, i.e., in the area of piston and valves, high temperature is also at the turbocharger. However, oxidation also occurs in the crankcase due to the presence of hot flue gases, which penetrate here from the engine cylinders. These bring high temperature and exhaust gases (and with them NOx) to the crankcase. Air and oxygen are always present in the crankcase, sometimes due to the crankcase ventilation. The oil is well mixed in the crankcase, the casing walls, crankshaft, etc., are covered with it, and the oil, therefore, has a large surface in contact with hot flue gases and air. There are, therefore, ideal conditions for oxidation and also for nitration of the oil. Nitration is then caused by the action of nitrogen oxides on the oil, where the product is organic nitrates. As the oil oxidizes, the antioxidant ZDDP decreases; the correlation between these variables was moderately strong, $\mathrm{R}=-0.72(p=0.002)$. However, somewhat surprising was the relatively significant positive correlation $\mathrm{R}=0.94(p<<0.001)$ between oxidation and sulfation, given that current diesel was of good quality and can contain a maximum of 10 ppm sulfur (S) [56]. The authors of this article believe that the answer can be found in a significant negative correlation $R=-0.87(p<<0.001)$ between ZDDP content and sulfation products. Dörr et al. [12,38] reported that the degradation products of ZDDP are sulfuric acid and phosphoric acid. Therefore, the authors of this article believe that the sulfation products are predominantly formed by the reaction of sulfuric acid as a decomposition product of ZDDP with the base motor oil, to a lesser extent by the reaction of $\mathrm{SO}_{x}$ from the exhaust gases with the base oil. Thus, a very strong correlation between sulfation and nitration can be explained $\mathrm{R}=0.97(p<<0.001)$. Sulfation can cause an increase in viscosity and the formation of varnishes, sludges, and sediments. According to the authors, the degradation products of oxidation, nitration, and sulfation are the cause of better lubricating properties of worn motor oils than fresh motor oils. Base motor oil composed of hydrocarbons is non-polar in nature. The products that are formed during oxidation, nitration, and sulfation changes are polar in nature, i.e., they adhere better to the lubricated surfaces of interacting components and have a positive effect on the lubricity of oils. For this reason, even the depletion of ZDDP-type antioxidants may not have the effect of increasing wear, as has already been demonstrated in the partial results presented in this article. Correlation analysis confirmed that there is a significant negative relationship $\mathrm{R}=-0.87$ ( $p<<0.001)$ between the fuel content of the motor oil and its KV. Too low oil viscosity can mean a thin lubricating film that has a low load capacity. The integrity of the lubricating film may be compromised. This can lead to the increased engine wear, which is greater, the higher the fuel content of the oil is, and the lower the viscosity is.

\section{Conclusions}

Contamination and degradation of lubricants are the main causes of unexpected tribological system failures. The aim of the presented work was, therefore, to explain the effect of chemical degradation and contamination (soot, fuel, moisture) of motor oils on the behavior of the lubricating film with respect to its load-bearing capacity, i.e., lubricity. Based on the results of the experiments, the authors came to the following conclusions:

- Current motor oils used in Czech Railways motor trains have excellent lubricity, which they retain throughout their service life.

- The lubricating properties of motor oils are not limited by the depletion of the antioxidant and anti-wear additive ZDDP and a high degree of chemical degradation. Chemical degradation products (oxidation, nitration, and especially sulfation products), which, unlike hydrocarbons, are of a polar nature, ensure better adhesion of the lubricant to lubricated components. The sulfur contained in the sulfation products also increases the lubricity. For these reasons, some oils had better lubricity at the end of the change interval than fresh oils. 
- Correlation analysis confirmed a relatively strong significant correlation between oxidation, nitration, and sulfation products $(R \geq 0.90)$. At the same time, these chemical degradation products are significantly negatively correlated with the concentration of ZDDP, i.e., with the loss of this additive.

- Due to the low concentration of sulfur in fuels on the European market, the formation of sulfation products can be explained mainly by the reaction of sulfuric acid as a decomposition product of ZDDP with the base motor oil, to a lesser extent as the reaction of $\mathrm{SO}_{x}$ from exhaust gases with the base motor oil.

- No significant effect of chemical degradation products on the kinematic viscosity value of motor oils has been demonstrated. However, in none of the analyzed samples did the concentration of these products exceed the limit value.

- Contamination of oil with diesel has the most significant effect on reducing the viscosity of motor oil; this result was supported by a high correlation between the variables. Even with a high concentration of diesel in the oil, the lubricating film of the tested samples retained its load-bearing capacity. Contamination of motor oils with soot did not confirm a significant increase in viscosity, but the concentration of soot did not reach the limit values given in the literature.

- It has been demonstrated that the low water contamination in motor oil does not cause a significant negative effect on lubricity, which led to the observation that the water droplets do not come into tribological contact but bypass it.

- The lubricity and anti-wear properties of motor oils are not factors that would limit the life of motor oils.

The presented results of the evaluation of the influence of physicochemical degradation and contamination of motor oils on lubricity are valid for the studied group of oils. The number of experiments needs to be expanded to generalize the results.

Supplementary Materials: The following are available online at https:/ /www.mdpi.com/2079-641 2/11/1/60/s1. Figure S1-1. The wear surfaces of steel rollers from the lubricity test of motor oils M7ASD III. Figure S1-2. The wear surfaces of steel rollers from the lubricity test of motor oils M7ASD V. Figure S1-3. The wear surfaces of steel rollers from the lubricity test of motor oils Urania LD. Figure S1-4. The wear surfaces of steel rollers from the lubricity test of motor oils OMV. Figure S21. FTIR spectrum of motor oils M7ADS III. Figure S2-2. FTIR spectrum of motor oils M7ADS V. Figure S2-3. FTIR spectrum of motor oils Urania LD. Figure S2-4. FTIR spectrum of motor oils OMV.

Author Contributions: Conceptualization, M.S. and I.H.; methodology, M.S. and I.H.; software, M.S.; validation, P.J. and M.S.; formal analysis, M.S. and I.H.; investigation, I.H.; resources, M.S., P.J., M.N. and O.V.; data curation, M.S.; writing — original draft preparation, M.S., P.J. and O.V.; writing-review and editing, M.S. and M.N.; visualization, P.J.; supervision, M.S.; funding acquisition, M.S. and I.H. All authors have read and agreed to the published version of the manuscript.

Funding: The authors wish to thank the University of Pardubice for funding the presented work.

Institutional Review Board Statement: Not applicable.

Informed Consent Statement: Not applicable.

Data Availability Statement: Not applicable.

Conflicts of Interest: The authors declare no conflict of interest.

\section{References}

1. Krupka, I.; Svoboda, P.; Hartl, M. Effect of surface topography on mixed lubrication film formation during start up under rolling/sliding conditions. Tribol. Int. 2010, 43, 1035-1042. [CrossRef]

2. Krupka, I.; Hartl, M.; Svoboda, P. Effects of surface topography on lubrication film formation within elastohydrodynamic and mixed lubricated non-conformal contacts. Proc. Inst. Mech. Eng. Part J J. Eng. Tribol. 2010, 224, 713-722. [CrossRef]

3. Sejkorová, M.; Hurtová, I.; Glos, J.; Pokorný, J. Definition of a motor oil change interval for high-volume diesel engines based on its current characteristics assessment. Acta Univ. Agric. Silvic. Mendel. Brun. 2017, 65, 481-490. [CrossRef]

4. Wei, L.; Duan, H.; Chen, S.; Jia, D.; Jin, Y.; Qian, X.; Liu, J.; Li, J. Discussion on the influence of driving parameters of civilian cars on motor oil degradation. Proc. IMechE Part J 2019, 233, 281-288. [CrossRef] 
5. Sejkorová, M.; Šarkan, B.; Caban, J.; Marczuk, A. On relationship between infrared spectra of worn out engine oils and their kinematic viscosity. Przem. Chem. 2018, 97, 49-54. [CrossRef]

6. Wolak, A.; Zajac, G. The kinetics of changes in kinematic viscosity of engine oils under similar operating conditions. Maint. Reliab. 2017, 19, 260-267. [CrossRef]

7. Macián, V.; Tormos, B.; Bastidas, S.; Pérez, T. Improved fleet operation and maintenance through the use of low viscosity engine oils: Fuel economy and oil performance. Maint. Reliab. 2020, 22, 201-211. [CrossRef]

8. Agocs, A.; Budnyk, S.; Besser, C.; Ristic, A.; Frauscher, M.; Ronai, B.; Dörr, N. Production of Used Engine Oils with Defined Degree of Degradation in a Large-scale Device. Acta Tech. Jaurinensis 2020, 13, 131-150. [CrossRef]

9. Skrzek, T.; Rucki, M.; Górski, K.; Matijošius, J.; Barta, D.; Caban, J.; Zarajczyk, J. Repeatability of High-Pressure Measurement in a Diesel Engine Test Bed. Sensors 2020, 20, 3478. [CrossRef]

10. Spikes, H. Friction Modifier Additives. Tribol. Lett. 2015, 60, 5. [CrossRef]

11. Zhang, J.; Ewen, J.P.; Ueda, M.; Wong, J.S.S.; Spikes, H.A. Mechanochemistry of Zinc Dialkyldithiophosphate on Steel Surfaces under Elastohydrodynamic Lubrication Conditions. ACS Appl. Mater. Interfaces 2020, 12, 6662-6676. [CrossRef] [PubMed]

12. Dörr, N.; Brenner, J.; Ristić, A.; Ronai, B.; Besser, C.; Pejaković, V.; Frauscher, M. Correlation between engine oil degradation, tribochemistry, and tribological behavior with focus on ZDDP deterioration. Tribol. Lett. 2019, 67, 62. [CrossRef]

13. Nicholls, M.A.; Do, T.; Norton, P.R.; Kasrai, M.; Bancroft, G.M. Review of the lubrication of metallic surfaces by zinc dialkyldithiophosphates. Tribol. Int. 2005, 38, 15-39. [CrossRef]

14. Zhang, J.; Spikes, H. On the mechanism of ZDDP antiwear film formation. Tribol. Lett. 2016, 63, 24. [CrossRef]

15. Thersleff, T.; Jenei, I.Z.; Budnyk, S.; Dörr, N.; Slabon, A. Structure and Formation of Soot Particles from Tribofilm Decomposition under Real Engine Conditions. ChemRxiv 2020. [CrossRef]

16. Gołębiowski, W.; Wolak, A.; Zając, G. The influence of the presence of a diesel particulate filter (DPF) on the physical and chemical properties as well as the degree of concentration of trace elements in used engine oils. Pet. Sci. Technol. 2019, 37, 746-755. [CrossRef]

17. Hurtová, I.; Sejkorová, M. Analysis of engine oils using modern methods of tribotechnical diagnostics. Perner's Contacts 2016, 11, 47-53.

18. Jablonický, J.; Simikić, M.; Tulík, J.; Tomić, M.; Hujo, L'.; Kosiba, J. Monitoring of Selected Physical and Chemical Parameters of Test Oil in the Wet Disc Brake System. Acta Technol. Agric. 2020, 23, 46-52. [CrossRef]

19. Jakóbiec, J.; Budzik, G. Czynniki mające wpływ na stopień degradacji oleju silnikowego w okresie eksploatacji. Arch. Motor. 2007, 3, 209-216.

20. Ziółkowska, M. Wpływ sadzy na proces żelowania oleju silnikowego. Nafta-Gaz 2019, 3, 178-184. [CrossRef]

21. Bagi, S.; Kamp, C.J.; Sharma, V.; Aswath, P.B. Multiscale characterization of exhaust and crankcase soot extracted from heavy-duty diesel engine and implications for DPF ash. Fuel 2020, 282, 118878. [CrossRef]

22. Salehi, F.M.; Morina, A.; Neville, A. Zinc dialkyldithiophosphate additive adsorption on carbon black particles. Tribol. Lett. 2018, 66, 118. [CrossRef]

23. Salehi, F.M.; Morina, A.; Neville, A. The effect of soot and diesel contamination on wear and friction of engine oil pump. Tribol. Int. 2017, 115, 285-296. [CrossRef]

24. Vyavhare, K.; Bagi, S.; Patel, M.; Aswath, P.B. Impact of Diesel Engine Oil Additives-Soot Interactions on Physiochemical, Oxidation, and Wear Characteristics of Soot. Energy Fuels 2019, 33, 4515-4530. [CrossRef]

25. Penchaliah, R. Tribological Effects of Diesel Engine Oil Contamination on Steel and Hybrid Sliding Contacts. In Tribology in Materials and Applications. Materials Forming, Machining and Tribology; Katiyar, J., Ramkumar, P., Rao, T., Davim, J., Eds.; Springer: Cham, Switzerland, 2020. [CrossRef]

26. Šarkan, B.; Caban, J.; Marczuk, A.; Vrabel, J.; Gnap, J. Composition of exhaust gases of spark ignition engines under conditions of periodic inspection of vehicles in Slovakia. Przem. Chem. 2017, 96, 675-680. [CrossRef]

27. Macián, V.; Tormos, B.; Gómez, Y.A.; Salavert, J.M. Proposal of an FTIR methodology to monitor oxidation level in used engine oils: Effects of thermal degradation and fuel dilution. Tribol. Ttrans. 2012, 55, 872-882. [CrossRef]

28. Hurtová, I.; Sejkorová, M.; Verner, J. A study of diesel particulate filter impact on engine oil quality. In Transport Means: Proceedings of the International Scientific Conference; Kaunas University of Technology: Palanga, Lithuenia, 2019.

29. Wei, L.; Duan, H.; Jin, Y.; Jia, D.; Chen, S.; Liu, J.; Li, J. Oil change interval evaluation of civilian cars in urban traffic condition. Proc. Inst. Mech. Eng. Part J 2019, 233, 956-964. [CrossRef]

30. Wei, L.; Duan, H.; Jin, Y.; Jia, D.; Cheng, B.; Liu, J.; Li, J. Motor oil degradation during urban cycle road tests. Friction 2020. [CrossRef]

31. Wolak, A.; Krasodomski, W.; Zając, G. FTIR analysis and monitoring of used synthetic oils operated under similar driving conditions. Friction 2020, 8, 995-1006. [CrossRef]

32. Vališ, D.; Žák, L.; Pokora, O. Perspective approach in using anti-oxidation and anti-wear particles from oil to estimate residual technical life of a system. Tribol. Int. 2018, 118, 46-859. [CrossRef]

33. Vališ, D.; Gajewski, J.; Žák, L. Potential for using the ANN-FIS meta-model approach to assess levels of particulate contamination in oil used in mechanical systems. Tribol. Int. 2019, 135, 324-334. [CrossRef]

34. Raposo, H.; Farinha, J.T.; Fonseca, I.; Ferreira, L.A. Condition Monitoring with Prediction Based on Diesel Engine Oil Analysis: A Case Study for Urban Buses. Actuators 2019, 8, 14. [CrossRef] 
35. Kučera, M.; Kopčanová, S.; Sejkorová, M. Lubricant Analysis as the Most Useful Tool in the Proactive Maintenance Philosophies of Machinery and its Components. Manag. Syst. Prod. Eng. 2020, 28, 196-201. [CrossRef]

36. Fernandes, W.; Tomanik, E.; Moreira, H.; Cousseau, T.; Pintaude, G. Effect of Aged Oils on Ring-Liner Wear. SAE Int. J. Fuels Lubr. 2020, 13, 167-176. [CrossRef]

37. Ma, Y.; Zhao, W.; Li, S.; Jin, Y.; Wang, Y.; Simon, T.C. Lubricating Durability of Two GF Category Engine Oils. Ind. Lubr. Tribol. 2005, 57, 161-167. [CrossRef]

38. Dörr, N.; Agocs, A.; Besser, C.; Ristić, A.; Frauscher, M. Engine oils in the field: A comprehensive chemical assessment of engine oil degradation in a passenger car. Tribol. Lett. 2019, 67, 68. [CrossRef]

39. Berglund, K. Lubricant ageing effects on wet clutch friction characteristics. Proc. Inst. Mech. Eng. Part J J. Eng. Tribol. 2010, 224, 639-647. [CrossRef]

40. Wang, L.; Wang, L.; Li, G.; Xu, X. Effect of Ash-Less Antioxidants on Fuel Efficiency Retention of PCMO Containing MoDTC. In Proceedings of the FISITA 2012 World Automotive Congress; Springer: Berlin/Heidelberg, Germany, 2013; pp. $483-491$.

41. Sikora, G. The studies on lubricity and contamination analysis of the personal car's lubricating oil with taking oil ageing into account. J. KONES 2013, 20, 375-379.

42. Černý, J.; Bučko, L.; Václavíčková, I. Mazivostní a Protioděrové Vlastnosti Motorových Olejů. Available online: http:/ / www. petroleum.cz/upload/aprochem2007_169.pdf (accessed on 10 October 2020).

43. Höhn, B.R.; Michaelis, K.; Weiss, R. Influence of Lubricant Ageing on Gear Performance. Materiaty 2001, 2, 363.

44. Kew Engineering. Oil Aging and Degradation: Why do I Need to Change the Oil? Available online: kewengineering.co.uk (accessed on 30 October 2020).

45. Sikora, G.; Miszczak, A. The influence of oil ageing on the change of viscosity and lubricity of engine oil. Solid State Phenom. 2013, 199, 182-187. [CrossRef]

46. Maguire, E. Monitoring of Lubricant Degradation with RULER and MPC. Master's Thesis, Linköping University, Linköping, Sweden, 2010. Available online: http:/ / www.diva-portal.org/smash/get/diva2:32-8033/FULLTEXT01.pdf (accessed on 10 October 2020).

47. ASTM D-7042. Standard Test Method for Dynamic Viscosity and Density of Liquids by Stabinger Viscometer (and the Calculation of Kinematic Viscosity); ASTM International: West Conshohocken, PA, USA, 2004.

48. Sejkorová, M. Application of FTIR spectrometry using multivariate analysis for prediction fuel in engine oil. Acta Univ. Agric. Silvic. Mendel. Brun. 2017, 65, 933-938. [CrossRef]

49. Man, J.; Zhao, J.; Song, L.; Yang, H. Study the Influence of Surface Morphology and Lubrication Pressure on Tribological Behavior of 316L-PTFE Friction Interface in High-Water-Based Fluid. Coatings 2020, 10, 405. [CrossRef]

50. Tripathi, A.K.; Vinu, R. Characterization of thermal stability of synthetic and semi-synthetic engine oils. Lubricants 2015, 3, 54-79. [CrossRef]

51. Sejkorová, M. Tribotechnical diagnostics as a tool for effective management of maintenance. Perner's Contacts 2015, 10, 126-136.

52. Koutný, D. Experimentální Studium Chování Mazacích Filmů Kontaminovaných Vodou. Brno University of Technology, Faculty of Mechanical Engineering. 2008. Available online: ustavkonstruovani.cz (accessed on 30 October 2020).

53. Booser, E.R. CRC Handbook of Lubrication and Tribology, Volume III: Monitoring, Materials, Synthetic Lubricants, and Applications; Scotia: Toronto, ON, Canada; CRC Press: Boca Raton, FL, USA, 1993; p. 71.

54. Kral Jr, J.; Konecny, B.; Kral, J.; Madac, K.; Fedorko, G.; Molnar, V. Degradation and chemical change of longlife oils following intensive use in automobile engines. Measurement 2014, 50, 34-42. [CrossRef]

55. Černý, J.; Strnad, Z.; Šebor, G. Composition and Oxidation Stability of SAE 15W-40 Engine Oils. Tribol. Int. 2001, 34, 127-134. [CrossRef]

56. Bringlerová, N.; Zbuzek, M.; Vráblík, A.; Hamerníková, J.; Černý, R. Application of Alternative Methods of Fuel Desulphurization. Chem. Listy 2018, 112, 827-832.

57. Wolak, A.; Zając, G.; Fijorek, K.; Janocha, P.; Matwijczuk, A. Experimental Investigation of the Viscosity Parameters Ranges-Case Study of Engine Oils in the Selected Viscosity Grade. Energies 2020, 13, 3152. [CrossRef]

58. Sejkorová, M. Determination of Total Alkalinity of Motor Oil by FTIR Spectroscopy. Chem. Listy 2013, 107, 643-647. 